\title{
Mujeres en el franquismo: una propuesta didáctica desde la historia oral
}

\section{Women and Francoism: a proposal from the oral history teaching}

\section{Matilde Peinado Rodríguez}

Universidad de Jaén

Resumen: Hacer posible el diálogo intergeneracional desde las aulas permite enriquecer, complejizar y entender las pervivencias del mismo en el marco personal, familiar y social, en las generaciones pasadas y, fundamentalmente, en las futuras, aportando nuevos argumentos para la construcción de la Historia Social del franquismo.

Por ello, el objeto de estudio van a ser las madres y abuelas del alumnado de $4^{\circ}$ de Educación Secundaria, mujeres que nacieron en los años 40-50 y en los albores de la transición, respectivamente, utilizando como metodología de trabajo la historia oral, que tienen enormes potencialidades didácticas, en base a un cuestionario abierto en torno a grandes áreas temáticas como formación, situación laboral y doméstica de la mujer, matrimonio, soltería femenina o aprendizaje invisible.

Palabras clave: Propuesta didáctica, enseñanza-aprendizaje, diálogo intergeneracional, investigación, historia oral.

Abstract: Make possible the intergenerational dialogue from classrooms allow enriching, diversified and understand the survival of the same in the context of personal, family and social; in past generations and, most importantly, in the future: only in this way is can provide new arguments for the construction of Social history in Spain.

Therefore, the object of study will be the mothers and Grandmothers of students of secondary education in two subjects, social studies (history) and education ethic - civic, women who were born in the 40-50's and at the beginning of the transition, respectively, using oral history as a working methodology which have enormous educational potential based on a questionnaire opened around large thematic areas such as training, employment and domestic situation of women, marriage, singleness female or invisible learning.

Keywords: Proposal didactic, teaching and learning, intergenerational dialogue, research, oral history.

(Fecha de recepción: mayo, 2014, y de aceptación: septiembre, 2014)

DOI: 10.7203/DCES.28.3734 


\section{Contextualización}

"Es un placer inmenso escuchar a los demás. Historiar, es sobre todo, dialogar con los otros, las mayorías salen del silencio y entran en la historia ${ }^{1 "}$

El modelo de mujer impuesto por el franquismo: "cristiana piadosa, madre ejemplar, esencia de femenidad, orgullo de España" fue, no sólo uno de los mayores éxitos ideológicos del franquismo, sino una pieza fundamental en su política de dominio económico y social, que se desarrolló en tres ámbitos: el concepto de feminidad, el ejercicio permanente de jerarquización y exclusión social y la aplicación férrea del sistema patriarcal en el ámbito familiar y, por extensión, en la sociedad (Peinado, 2012, p. 17).

El patriarcado ${ }^{2}$ ha sido y continúa siendo uno de los sistemas sociales más exitosos en la conversión de una construcción cultural, por la vía de la imposición, la perpetuación y la interiorización, en un hecho "natural", "innato" a la existencia humana, hasta el punto de lograr la identificación unívoca entre familia y familia patriarcal, de la que se deriva la asignación jerarquizada de roles en función de la edad y, fundamentalmente, del género.
El periodo franquista supuso para dicha institución una nueva edad de oro, un espaldarazo a su dominio y perpetuación: la formación y educación femenina debía ir encaminada a la plena identificación con un modelo cultural propio, específico para su género, dotado de unas particulares virtudes que constituyen la esencia de la "mujer de su casa" de "una mujer decente", cuyos fundamentos y pervivencias nos proponemos entender, analizar y contextualizar a través de las voces de las que serán en este proyecto nuestras protagonistas, las abuelas de nuestro alumnado, que crecieron bajo el nacionalcatolicismo y sus madres, que nacieron en la etapa final de la dictadura franquista, incluso en la transición, pero en cuyo proceso formativo se han perpetuado algunos de dichos fundamentos, pues ellas simbolizan una modelización de niñas y jóvenes que formaba parte no sólo de un sistema estatal formativo, sino en un sentido amplio, de la cultura dominante ${ }^{3}$.

Nos interesa su visión de la vida, su destino social, sus anhelos, sus autoimposiciones, en definitiva, su universo familiar, porque, como expone Olga Cabrera (2008, p. 30), las mujeres tienen una visión colectiva, aunque limi-

\footnotetext{
${ }^{1}$ Mercedes Villanova (opus cit THOMPSON, 1988:14).

${ }^{2}$ Adrianne Rich (1999) definió el patriarcado como "el poder de los padres", un sistema familiar y social, ideológico y político en el que los hombres, a través de la fuerza, la presión directa, los rituales, la tradición, la ley o el lenguaje, las costumbres, la etiqueta, la educación o la división del trabajo, determinan cuál es el papel que las mujeres deben interpretar con el fin de estar en todas las circunstancias sometidas al varón.

${ }^{3}$ Barranquero Texeira (2012:12) opus cit Peinado Rodríguez (2012).
} 
tada a la familia, con un tiempo marcado en gran medida por "las necesidades de mis hijos", las enfermedades, los nacimientos.. y rara vez utilizan en sus narraciones el singular.

Nos proponemos reflexionar sobre las pervivencias ideológicas del patriarcado en sus vidas y su transmisión a las siguientes generaciones, contribuyendo a la deshistorización y eternización de la división funcional de la sexualidad y la plena identificación entre sexo y género, un proceso social en el que es necesario seguir profundizando, como afirmara Morales Morente (2007, p. 216), pues si queremos entender sobre qué bases reside el poder de género, comenzar por el análisis de la ideología de la mujer es el camino idóneo.

Investigar la influencia de la ideología y la cultura en el ámbito educativo español así como su proyección social en el siglo XX, desde la perspectiva de género, nos ofrece nuevas herramientas de reflexión para entender la pluralidad de caminos recorridos por las mujeres como resultado no sólo de un análisis de género, sino también de clase, y analizar en última instancia por qué es tan difícil la consecución real de la igualdad en nuestro país.

Por ello, defiendo que la actual legislación educativa así como sus acciones en pro de la igualdad entre hombres y mujeres debe partir de una reflexión en torno a las pervivencias del patriarcado en la sociedad actual, a través de las mujeres que vivieron en el franquismo y educaron en este contexto a sus hijos $y$, fundamentalmente, a sus hijas. Las madres, en el seno de los hogares, ejercen un papel determinarte como transmisoras de normas, valores y creencias para las generaciones venideras, $y$, en este periodo, fueron en gran medida transmisoras de todo un corpus ideológico de la vida en femenino enormemente rentable a los intereses del estado franquista.

Existe una amplia y extensa trayectoria historiográfica en torno al patriarcado o el modelo de mujer diseñado por el estado franquista, pero la reflexión de dicha institución a partir de las creencias, valores y principios de las mujeres que se formaron en aquella época es una línea de investigación que se inició en las dos última décadas del siglo XX, con trabajos de investigación ya clásicos como, los realizados por Amparo Moreno (1987), Marina Subirats (1988,1994), Pilar Ballarín (2001) o Montserrat Moreno (2000), entre otros, y sus aplicaciones al campo de la educación meramente testimoniales.

Hacer posible el diálogo intergeneracional desde las aulas permite enriquecer, complejizar y entender las pervivencias del mismo en el marco personal, familiar y social; en las generaciones pasadas $\mathrm{y}$, fundamentalmente, en las futuras: sólo de esta forma se podrá aportar nuevos argumentos para la construcción de la Historia Social durante el franquismo, sin los cuales no puede entenderse la realidad social española, especialmente femenina, del siglo XXI.

Por último, son pocas las propuestas didácticas que tratan de crear espacios 
de reflexión entre jóvenes y mayores y fomentar la comprensión, el diálogo y la construcción de una cotidianidad en armonía e igualdad, y ello a pesar de que realidades como el aumento en la esperanza de vida, que está haciendo posible que varias generaciones de una misma familia puedan compartir su vida juntas o la incorporación de la mujer al mundo laboral(Triadó y Villar, 2008), que ha incrementado de forma significativa la presencia cuidadora y educadora de las abuelas.

\section{Objeto de estudio}

Las abuelas de hoy, niñas de los años 30, 40 y 50 del siglo XX, son hijas de un sistema educativo que forjó muchos de los principios éticos, morales y religiosos que continúan en la esencia de lo que piensan sobre la organización social, los roles genéricos, la familia... una manera de entender la vida que siguen en gran medida transmitiendo a las generaciones futuras, pues muchas de ellas son cuidadoras y educadoras de primer orden de la infancia española actual.

Ahora bien, a pesar de que nos hemos posicionado desde el principio en contra de un modelo de feminidad y un sistema patriarcal que es injusto, desigualitario, jerarquizante y excluyente con el colectivo femenino, es fundamental que nuestro alumnado valore cómo sus abuelas, y posteriormente sus madres, a pesar del encorsetamiento personal, moral, religioso o institucional, lucha- ron, dentro de los estrechos márgenes para la libertad, para la reflexión, para los comportamientos desviados de una norma impuesta a golpe de persecución, la obediencia, amenaza de pecado y el miedo, por sus derechos y los de sus hijas, para romper, como expone Rodríguez López (2014) "los muros del franquismo" a nivel político, social pero sobre todo ideológico, un largo trecho que avanza por acciones individuales que sentaron las bases del sistema legal y jurídico que disfrutamos en la actualidad. No pretendemos únicamente que la entrevista permita conocer los acontecimientos del pasado sino, como afirma Benadiba (2013, p.30), que se convierta en una herramienta para interpretar un pasado del que forman parte entrevistada y entrevistador/a.

La propuesta didáctica está pensada para el alumnado de $4^{\circ}$ de E.S.O, en el marco de las siguientes asignaturas: Ciencias Sociales (Historia), donde trabajaremos desde la unidad didáctica denominada "España: 1898-1975”, y en concreto en relación al epígrafe "Las características ideológicas del franquismo" y en la asignatura "Educación ético-cívica", también del mismo curso, en el bloque denominado "La igualdad entre hombres y mujeres", y en concreto en relación al epígrafe "Causas y factores de discriminación de las mujeres”.

Hemos de considerar, por otra parte, que se trata del último cuso de la formación obligatoria, una parte del alumnado no volverá a cursar la asignatura de Historia mientras otro grupo de ellos volverán a estudiar Historia de España 
en $2^{\circ}$ Bachillerato, situación que hace indispensable profundizar en los fundamentos ideológicos, políticos y sociales de un sistema político que protagoniza la historia del siglo XX en nuestro país.

Partiendo de la teoría feminista socioconstruccionista, que intenta conocer el proceso de construcción del patriarcado para llegar a su deconstrucción, nos proponemos poner en tela de juicio la teoría esencialista de la división de géneros. Es decir, pretendemos mostrar y demostrar cómo no existen identidades sexuales fijas, esenciales, sino que el "ser mujer" o "ser hombre" es una entidad que se construye socialmente.

En relación con este planteamiento, la Ley Orgánica 2/2006 señala que La Educación Secundaria Obligatoria contribuirá a desarrollar en los alumnos y las alumnas las capacidades que les permitan:

a) Asumir responsablemente sus deberes, conocer y ejercer sus derechos en el respeto a los demás, practicar la tolerancia, la cooperación y la solidaridad entre las personas y grupos, ejercitarse en el diálogo afianzando los derechos humanos como valores comunes de una sociedad plural y prepararse para el ejercicio de la ciudadanía democrática.

b) Valorar y respetar la diferencia de sexos y la igualdad de derechos y oportunidades entre ellos. Rechazar los estereotipos que supongan discriminación entre hombres y mujeres. c) Fortalecer sus capacidades afectivas en todos los ámbitos de la personalidad y en sus relaciones con los demás, así como rechazar la violencia, los prejuicios de cualquier tipo, los comportamientos sexistas y resolver pacíficamente los conflictos.

Con tal finalidad, las Administraciones públicas deben promover la inclusión, en los planes de estudio en que proceda, de enseñanzas en materia de igualdad entre mujeres y hombres, así como las investigaciones especializadas en dicha materia y su aplicación al ámbito educativo.

Como puede apreciarse, actualmente disponemos de un amplio marco legal en materia de igualdad; sin embargo, en términos generales, no se ha producido en el ámbito educativo una reflexión en torno a la herencia cultural femenina en la que nacemos, pensamos y vivimos necesaria para hacer posible la igualdad en todos los ámbitos de la realidad social.

Siguiendo la línea argumental expuesta nos proponemos dos objetivos generales:

a) Entender las pervivencias del sistema patriarcal y el modelo de mujer impuesto por el franquismo en el ideario cultural, ideológico, mental de tres generaciones: las abuelas, que nacieron en los años 40 y 50, las madres, nacidas entre los años 60 y 70 y el propio alumnado, con el fin de realizar simultáneamente un análisis comparativo y evolutivo entre las tres 
generaciones en clave de género y clase social.

b) Crear un marco idóneo para el diálogo intergeneracional que posibilite a nuestros alumnos y alumnas entender a sus abuelas y su madres en el marco cronológico y espacial que les tocó vivir, proporcionando nuevos argumentos para la creación de un marco de convivencia óptimo e imprescindible en el camino hacia la igualdad.

Estos objetivos generales se complementan con los siguientes objetivos específicos:

$1^{\circ}$ Hacer visible su labor como educadoras en la construcción social de los géneros, con respecto a sus hijos/as y nietos/as.

$2^{\circ}$ Estudiar y deconstruir la formación androcéntrica y religiosa de esas mujeres en los tres ámbitos en que se desenvuelven: personal, familiar y social.

$3^{\circ}$ Analizar y revelar la importancia del franquismo como sustento de una sociedad patriarcal fuertemente jerarquizada en cuanto a los géneros.

$4^{\circ}$ Valorar la contribución personal de muchas de estas mujeres en la lucha contra la desigualdad de género.

\section{En torno a la metodología: las potencialidades didácticas de la Historia Oral}

“...la palabra hablada ilumina la escrita, revitalizándola y dándole la perspectiva y el contorno humano adecuado" 4

Feliu y Hernández (2013) afirman que las percepciones de los testigos son entendidas como fuentes primarias para entender un determinado hecho o situación histórica. La memoria de las personas puede ser recogida, consultada y contrastada de diferentes maneras: entrevistas, cuestionarios, cuadernos, libros de memorias... el abanico de posibilidades al respecto es muy amplio, pero su utilidad en las aulas es incuestionable, tanto para la consecución de los objetivos, contenidos y competencias contemplados en el currículum como en clave metodológica, siempre desde la interacción con otras fuentes metodológicas (documentales y bibliográficas entre otras) ya trabajadas en el desarrollo de la asignatura.

Así, como defiende Benadina (2013), dotamos de herramientas metodológicas a un colectivo, nuestros estudiantes, que por estar fuera de los circuitos institucionales académicos establecidos, quedan privados de la posibilidad de que sus trabajos e investigaciones, en las que utilizan fuentes orales, reciban el reconocimiento que por su valor se merecen, y al mismo tiempo, como

${ }^{4}$ Thompson, P. (1988, p.10). 
argumenta Llona (2012, p.11), introducimos esta metodología en el contexto de la historia académica, al margen, en su mayoría, de los impulsos de la renovación historiográfica ${ }^{5}$. Por último, brindamos la posibilidad de que los resultados de dichos trabajos tengan una repercusión directa en el entorno en donde se han realizado y en las personas que han brindado su testimonio, de modo que sirva para la transformación social.

La fuente o documento oral como la memoria individual y colectiva fruto de la interacción pasado-presente, que se confecciona a través de la entrevista. Además de recuperar el testimonio de aquellos sujetos que vivieron y protagonizaron un hecho histórico, supone la recuperación del testimonio de determinados sectores de la población alejados de las esferas del poder, de los "sin historia": es la historia "desde abajo", la "Grass Roots History" la que nos interesa recuperar.

Desde los años 90 se ha revalorizado la historia oral (por una parte de los historiadores contemporáneos ${ }^{6}$ ), para recuperar la memoria colectiva ${ }^{7}$. Evidentemente, presenta como toda fuen- te, unas limitaciones, partiendo de la percepción subjetiva del entrevistado/a, así como errores u omisiones de datos, fechas o hechos históricos sobre los que se pregunta a los informantes, subjetividad que, por otra parte, también prevalece en la mayoría de las fuentes escritas; en nuestro caso, el peso de la las concepciones ideológicas es aún mayor, al centrarnos en la evolución cultural y mental del colectivo femenino; además, estamos convencidos de que la aportación de la historia oral no sólo enriquece la historia social sino aporta nuevas perspectivas de análisis hasta ahora no contempladas, y es especialmente útil para trascender la esfera de lo público y entender la articulación de la vida cotidiana desde su sistema de valores y creencias, reivindicando con ello que lo cotidiano también forma parte del discurso histórico, porque la memoria, como nos recuerda Llena (2012, p. 16 ) tiene una intervención decisiva en la construcción del sujeto y, consecuentemente, es una fuente privilegiada en el estudio de las identidades. Por supuesto, es necesario contrastar la información con otro tipo de fuentes, como las hemerográficas, bibliográficas, docu-

${ }^{5}$ No obstante Benadiba (2013, p.7) nos advierte de que la creciente profesionalización ha convertido a la Historia Oral en respetable académicamente, pero comporta el riesgo de apagar el entusiasmo, al introducir cautelas formales e instituir formas rutinarias enmascaradas de objetividad y neutralidad científica.

${ }^{6}$ Como expone Mercedes Villanova (opus cit Thompson, 1988:12), la fuente oral, en los años 70, tuvo el riesgo de convertirse en historia marginal por su actitud crítica y militante, en gueto de determinados historiadores, cuando precisamente su fuerza reside en situarse en el centro mismo de las polémicas historiográficas, en constante diálogo y crítica para buscar nuevos enfoques.

${ }^{7}$ Mercedes Vilanova, Cristina Borderías y Pilar Folguera son algunas de las investigadoras más relevantes en el campo de la historia oral, aportando reflexión teórica como formas de aplicación al aula. 
mentales, etc, en torno a las cuales se han articulado los contenidos del currículum que trabajaremos previamente con nuestro alumnado.

Sin embargo, siguen siendo pocas las propuestas educativas pensadas para vehiculizar el encuentro intergeneracional, para crear espacios de reflexión entre jóvenes y mayores, para fomentar la comprensión, el diálogo y la construcción de una cotidianidad en armonía e igualdad, a pesar de que son importantes y conocidas las investigaciones realizadas desde la historia oral que han tenido un impacto enriquecedor y transformación de la historia de las familias.

Desde el punto de vista educativo, al igual que el trabajo con otro tipo de fuentes requiere que el alumnado sea un agente activo de su propio aprendizaje, el trabajo con fuentes orales conlleva una alta dosis de motivación por el protagonismo que asume el alumnado-entrevistador, e implica un acercamiento a los mayores y un mayor grado de socialización entre generaciones. Además, los alumnos y alumnas dotan de nombre propio los hechos, tantas veces asimilados como ajenos y distantes, presentes en los contenidos del curriculum académico; estudiar historia permite entender la cotidianidad de nuestros antepasados y el futuro que construyeron para nosotros/as.

Otra potencialidad de entrevistar a sus mayores está relacionada, como nos recuerda Halbmayr (2010:159) con la doble finalidad de toda entrevista de Historia Oral: adquirir conocimientos sobre los hechos históricos y reconstruir la biografía del entrevistado, que es esencia, su propia biografía, la de un pasado familiar que permite entender la realidad de su presente, su proceso de formación integral en tanto que individuo con una proyección personal, familiar y, consecuentemente, social.

Tomando, por tanto, como instrumento metodológico la Historia Oral, entrevistarán a su madre y a una de sus abuelas sirviéndose de un cuestionario previamente establecido, que hemos distribuido por bloques temáticos precedidos de una justificación teórica donde realizamos una fundamentación histórica, desde los contenidos trabajados por el alumnado en las dos asignaturas marco de este trabajo, que les va a permitir no sólo entender y contextualizar las preguntas planteadas, sino fomentar su capacidad para la indagación y la investigación, dejando al final de cada uno de dichos bloques un espacio abierto a preguntas, reflexiones, curiosidades del alumnado surgidas al hilo de la entrevista realizada a sus familiares que podrán compartir con el resto de sus compañeros/ as durante la exposición posterior en el grupo-clase.

\section{$1^{\circ}$ Formación}

Pilar Ballarín (2001) afirma que la tradición educativa de las niñas españolas de la primera contemporaneidad hacía hincapié en los valores tradicionales y católicos así como en las herramientas útiles para el sostenimiento del 
hogar y de la familia. El sistema de educación español en el Franquismo retomó la prolongación de las pautas culturales y mentales fundamentadas en el constructo sexo/género, contribuyendo a la segregación social de las mujeres españolas. Con la ley de Educación Primaria de $1945^{8}$ comienza otra etapa de la escuela segregada que se desarrollará durante 30 años de franquismo, con unos objetivos claros en su intento educativo: hacer de las niñas unas perfectas amas de casa, esposas fieles al marido, madres amantísimas de sus hijas, castas y pudorosas, que deleguen confiadamente la gestión social y política a los hombres mientras cultivan los valores propios de la feminidad.

En este periodo, los niveles de analfabetismo femenino habían descendido considerablemente, acortando las distancias, aún presentes, con el colectivo masculino, pero es necesario resaltar las significativas diferencias existentes en los estudios medios y superiores. Cuando terminaban los estudios elementales, unas, se disponían a casarse, otras, a los escasos trabajos de y para mujeres y unas poquísimas, a las carreras universitarias cuya elección era implícitamente femenina, secundaria, propia de la mujer, como puericultora o enfermera, y si hacía carrera superior se le orientaba a las letras. El ideal femenino tradicional, que con tanto empeño rescató y difundió el franquismo, mostraba un prototipo de mujer de clase media cuya única carrera era el matrimonio y para las que el trabajo constituía una deshonra, como analizaremos más adelante.

\section{CUESTIONARIO}

¿Dónde naciste?

¿Qué estudios tienes?

¿Qué dificultades tenía la mujer en tus tiempos para acceder a la educación? ¿Repercutió en ello hacer nacido o crecido en un ámbito rural/urbano?

¿Las condiciones en el acceso a la educación media y superior eran mejores para los hombres?

¿Tienes hermanos varones? ¿Tienen una formación diferente de la tuya?

¿Cómo entendía la sociedad la formación de la mujer? ¿Qué debía estudiar y para qué?

¿Crees que los niños y las niñas deben recibir la misma educación o diferente? ¿En qué aspectos y por qué?

\section{$2^{\circ}$ Situación laboral y doméstica de la mujer \\ “... la "Ley de ayuda familiar" de marzo de 1946, penalizaba el trabajo de la mujer casada}

\footnotetext{
${ }^{8}$ El texto de la Ley de Educación Primaria de 17 de julio de 1945 (BOE, 18 de julio de 1945), elaborado por José Ibáñez Martín, primer ministro de Educación, incorporaba los valores de tradicionalismo, catolicismo y falangismo. (opus cit Huguet, 201:11).
} 
con la pérdida del plus familiar, considerando que ésta debía dedicarse plenamente a sus tareas como madre" 9

La legislación franquista se caracterizó, desde el Fuero del Trabajo de 1938, por una discriminación política y laboral de las mujeres, obligando a despedirlas de ciertas ocupaciones cuando contraían matrimonio ${ }^{10}$. La posterior legislación asistencial privó de alicientes al empleo femenino al conceder subsidios y prestaciones a las familias en las que la esposa permanecía en casa, poniendo fin a la protección de la maternidad que se contempló desde 1931, convencidos de "la necesidad de proteger a las familias con hijos o familias numerosas que permita mediante ayudas económicas que la mujer no trabaje fuera de casa, para que no se va obligada a permanecer excesivo tiempo fuera del hogar y los hijos queden abandonados" (Fernández, 1961). En los años 40 resurgieron las campañas que ensalzaban el prototipo ideológico del ama de casa mediante la identificación entre el concepto de bienestar y la dedicación exclusiva a los deberes domésticos; la ideología reinante tradujo el feliz destino hogareño en una práctica ejemplarizante, obligatoria y determinante para el bienestar futuro de sus hijos.

Para todas aquellas que renunciaban, acuciadas por la necesidad, a su exclusiva función social reproductora, como esposa y madre ejemplar, al amparo de consideraciones ideológicas trasnochadas, se generaron argumentos económicos y sociales para fundamentar su inferior capacitación laboral que la hacía, consecuentemente, merecedora de un salario inferior.

\section{CUESTIONARIO}

¿Has trabajado? Explica un poco la naturaleza de los diferentes trabajos realizados a lo largo de tu vida (remunerado o no, parcial o a tiempo completo, etc.).

¿Dejaste de trabajar cuando te casaste? ¿Por qué?

¿Cómo interpretabas tu condición de mujer trabajadora, ante los demás y ante ti misma? ¿Qué pensaba su marido de que trabajases?

¿Piensas que es posible conciliar la vida laboral y familiar? ¿Por qué?

¿Qué sentías cuando dejabas a tus hijos/as con otras personas para irte a trabajar?

$¿$ ¿rees que el lugar de una mujer es fundamentalmente su casa? ¿Por qué?

¿Cómo se repartía el ejercicio de las tareas domésticas en tu casa? ¿Colaboraban tu padre/tus hermanos varo-

9 Folguera, P. (2005:178).

10 También desde los planteamientos eugenésicos algunos médicos, como el militar Vallejo-Nájera apostaban por la eugenesia espiritual, que insistía en la necesidad de que las mujeres se apartaran de la vida laboral. 
nes, y posteriormente tu marido, en las tareas domésticas?

¿Cuánto tiempo estimas que dedicáis tu marido y tú a las tareas domésticas en la actualidad a las distintas responsabilidades de un hogar?

\section{$3^{\circ}$ Matrimonio}

La mujer fue impulsada a buscar marido como seguro de vida, y difícilmente podía rebelarse. Pilar Folguera (2005, p.179) relata cómo, en los años de la posguerra, el matrimonio suponía para muchas mujeres la posibilidad de escapar de la estrechez y, en muchos casos, de la miseria. Había que preparar y disponer desde su más temprana edad para el matrimonio, en lugar de una buena formación, encaminada a su propia subsistencia como ciudadana, la mejor formación era convertirse en madre y esposa ejemplar. Por otra parte, educar a las mujeres desde y para la sumisión y que ellas a su vez inculcaran a sus hijas dicha condición era garantía de asunción pasiva de los fundamentos del patriarcado en el ámbito familiar.

Creemos poder afirmar, y pretendemos que los alumnos/as y sus familiares dialoguen sobre ello, que el matrimonio tiene un protagonismo absoluto en el ideario femenino español de la segunda mitad del siglo XX y, además, que pervive en la actualidad en el concepto estético, cultural e institucional en la actualidad, más allá de la idea de familia. El matrimonio ideal, estereotipa- do, inalcanzable para la mayoría de las españolas, esa "ilusionada aspiración" fue también un pilar de estabilidad y consolidación en el estado franquista (Peinado y Anta, 2013).

\section{CUESTIONARIO}

¿A qué edad te casaste? ¿Cuánto tiempo duró su noviazgo?

¿Debe ser un objetivo de la mujer en la vida tener pareja o casarse? ¿Era lo deseable cuando tú eras una adolescente? ¿Soñabas con el matrimonio como tu destino ideal?

¿Crees que es importante que tus hijos/ hijas, nietos/as se casen o al menos vivan en pareja?

¿Es una condición "natural" e imprescindible de la mujer tener hijos?

¿Cuántos hijos/as has tenido? ¿Realizó una planificación de los hijos que quería tener? ¿Cuáles fueron los criterios que prevalecieron en dicha planificación?

\section{$4^{\circ}$ En torno a la soltería femenina}

La sociedad española estaba estructurada en torno al matrimonio, una organización que despoja a la mujer de su individualidad, de su existencia como sujeto, existe en referencia a otros, como esposa o su madre. Permanecer soltera no era entendido como una opción y, por tanto, las solteronas que habían sido incapaces de participar del mercado matrimonial eran un 
arquetipo femenino extraño al cuerpo social: seres desnaturalizados, dependientes, dignos de lástima.

Sin embargo, pretendemos desgranar con el alumnado las motivaciones reales de una concepción que no es puramente ideológica, sino que encierra de nuevo un interés económico y social por parte del estado franquista, pues las solteras, con su pretensión de "volar en solitario", su autosuficiencia económica ${ }^{11}$, podían cuestionar el patriarcado que tan bien servía a sus intereses y desequilibrar un mercado laboral organizado en clave masculina. La estigmatización de la soltería, de esta forma, resultó ser uno de los ejercicios más exitosos de afirmación del poder patriarcal como garante de la estabilidad familiar, socioeconómica y, consecuentemente, política (PEINADO RODRÍGUEZ, 2013).

Nuestra hipótesis de partida es que, aún hoy, "solterona" es un concepto peyorativo en su esencia, porque gran parte de los valores culturales y morales siguen vivos en las aspiraciones y frustraciones que experimentan muchas mujeres, en los roles familiares y socia- les que la sociedad nos asigna y que en gran medida nos autoimponemos.

\section{CUESTIONARIO}

¿Qué opciones existían para las muchachas que no se casaban?

¿Se sigue utilizando el término "solterona" o "quedarse para vestir santos"? ¿En qué casos y con qué sentido?

¿Piensas que las mujeres sin marido, sin un varón, son dignas de lástima? ¿Qué crees que piensa la sociedad espanola al respecto?

¿Cuál era la concepción en torno a la "solterona" en los años 50, 60 y 70 en España? ¿Y en la actualidad?

\section{$5^{\circ}$ El aprendizaje invisible}

En este apartado nos proponemos interpretar la influencia de lo que vamos a denominar como currículum oculto ${ }^{12}$, aquellas lecturas, consejos, discursos, reflexiones, ilustraciones, etc, presentes en las revistas para chicas o muchachas

${ }^{11}$ Nunca se contempló la posibilidad de que la mujer pudiera realizarse profesional y personalmente, sólo se toleraba en el caso de que la mujer no encontrara marido y tuviera que trabajar para "pasar con nobleza y dignidad sin el apoyo del hombre. Como recoge Climent Ferrer en su libro "El ama de casa" (1916:301) la experiencia enseña a las madres que el porvenir de las hijas es mucho más incierto que el de los hijos y que conviene al ama de casa tener de las diversas profesiones femeninas una noción que la oriente en la tarea de proporcionar a sus hijas un honrado medio de vivir por si Dios no las destina al matrimonio.

${ }^{12}$ Casanova Nuez (2009:76) nos recuerda que la mentalidad se va forjando por los orígenes sociales, lo que oigan en su casa y lo que enseñen en la escuela, la religión, las relaciones y el lugar de trabajo, las costumbres, lo que lean o lo que escuchen de manera inconsciente, lo que vean, el medio social en que se muevan, sus propias experiencias de la vida... todo ello construirá el universo cultural de referencia. 
casaderas, pero también en los libros de texto, en el catecismo, en los manuales de urbanidad... o en los seriales de la radio.

La familia, para el nacionalcatolicismo $^{13}$, era origen y prototipo de toda sociedad perfecta, centro y cuna de los valores cristianos, donde la mujeresposa-madre se convertía en la piedra angular de dicha estructura. El discurso oficial eclesiástico contemplaba una clara distinción en el comportamiento religioso en clave genérica: como la capacidad intelectual y formación de las mujeres era sensiblemente inferior, cuando no nula, su espiritualidad respondía a un estadio infantil, sentimental, apta únicamente para las formas externas de religiosidad, aquellas que la comunidad podía contemplar y juzgar como ejemplarizantes para toda mujer católica que se preciase.

Los contenidos de la formación moral y religiosa de las niñas debían ir encaminadas a garantizar la preparación de la mujer para la "misión natural" que le había encomendado Dios y el púlpito se convierte en el único medio de información y formación femenina de provincias. La religiosidad de las madres, transmitida amorosamente a sus hijos, sería el germen de la "recristianización" y redención moral de la sociedad. Además, como relata Ballarín (2001, p.114), al silencio, modestia, obediencia y sub- ordinación católicas tradicionales se unirían la suavidad, la dulzura, abnegación y sentido de la belleza reinarían en el interior del hogar.

\section{CUESTIONARIO}

a) Hablamos sobre las lecturas "para chicas" en tu época, los programas de radio, las canciones o el cine:¿Qué consejos daban? ¿Qué modelo de mujer defendían? ¿Cuál era el destino ideal de toda mujer? ¿Hablaban de su formación, de sus inquietudes intelectuales, de su independencia económica?

b) ¿Acudías a catequesis y a misa los domingos? ¿Recuerdas alguna homilía que hablara específicamente sobre la mujer (hábitos, costumbres, pecado, honradez, roles femeninos, la mujer en la familia, etc?

c) ¿Y las pautas al respecto que se aprendían en las clases de religión? ¿Qué importancia diría usted que tenía el discurso religioso oficial en su vida? ¿Y en la de su familia? ¿Y en sus compañeras y amigas?

\section{Propuesta didáctica}

Nuestra propuesta didáctica tiene dos ámbitos de actuación, el aula y los hoga-

\footnotetext{
${ }^{13}$ La Real Academia de la Lengua Española define el nacionalcatolicismo como doctrina y práctica caracterizada por la estrecha relación entre el Estado franquista y la Iglesia católica, y por la influencia de ésta en la sociedad.
} 
res, con unos protagonistas comunes en ambos, nuestro alumnado, que ejercerá la doble faceta de discentes, en una primera fase, e investigadores posteriormente, siendo el intercambio y enriquecimiento bidireccional con sus madres y abuelas, como venimos describiendo, el fundamento de nuestra propuesta.

Llegados a este punto ya hemos realizado con ellos una fase previa, donde se ha trabajado con el grupo-clase, detectando primeramente de dónde partíamos (evaluación inicial), para fundamentar un aprendizaje significativo de los objetivos y los contenidos relacionados con el currículum de las áreas de conocimiento implicadas, que en última instancia deben determinar el desarrollo competencial de nuestro alumnado, atendiendo fundamentalmente a las competencias social y ciudadana, cultural y artística y autonomía e iniciativa personal.

Seguidamente procedemos a explicar, también en el contexto del grupoclase, cómo se va a llevar a cabo la propuesta didáctica. El número de miembros implicados en la elaboración de las distintas fases de la propuesta es el criterio secuenciador y organizador de la misma: trabajo individual, trabajo en pequeño grupo (un número máximo de cinco personas en cada uno de ellos) y trabajo en gran grupo, que en este caso, y partiendo de la ratio oficial, se situarían en torno a 25 alumnos y alumnas.

\section{a) Trabajo individual.}

Iniciamos esta parte con un ejercicio de motivación tanto teórico, en torno a las potencialidades de la historia oral, como funcional o metodológico, donde la intención es despertar en nuestro alumnado el interés por investigar y conocer la proyección del pasado, con unos protagonistas hasta ahora anónimos para ellos, sus familiares, y cómo es posible construir, desde su percepción de la realidad, el discurso histórico.

A continuación nos detendremos en cada uno de los bloques temáticos del cuestionario, repasaremos los contenidos más significativos ya trabajados y realizaremos de nuevo una contextualización espacio-temporal que permita al alumno entender que, además de los aspectos que vamos a trabajar todos, en cada uno de los apartados, se abre un espacio de libertad para trascender un cuestionario que debe servir para orientar, nunca para encorsetar; podrán profundizar, relacionar con otras cuestiones, recoger anécdotas que ilustren las reflexiones y fundamentalmente dialogar entre ellos/as.

Es recomendable, aunque no será obligatorio, que trabajen primero con las abuelas y después con las madres o viceversa, y, en una segunda fase, realizar un encuentro abuela-madrealumno/a, pero la organización de las entrevistas será una decisión del alumnado, que podrá justificar en el debate posterior por qué ha optado por esta metodología.

Para recoger y transcribir las entrevistas nos serviremos de la grabadora del móvil, pues la totalidad de nuestros alumnos y alumnas disponen del mismo y con una calidad suficiente para gravar 
las entrevistas y posteriormente transcribirlas. De esta forma trabajaremos conjuntamente también las competencias lingüística y digital. Dispondrán de 15 días para hacer las entrevistas, considerando la disponibilidad de tiempo de los familiares así como la posibilidad de que no vivan en la misma localidad.

\section{b) Trabajo en pequeño grupo.}

1) Una vez realizadas y transcritas las entrevistas, el alumnado seleccionará aquellas frases o reflexiones de sus madres y abuelas que más le hayan llamado la atención para trabajarlas en pequeño grupo.

2) Entre todos/as los miembros del grupo reflexionaran sobre la posible evolución que se ha producido entre el pensamiento de sus abuelas y sus madres, señalando en qué aspectos y por qué.

3) Seguidamente se entablará un diálogo en torno a aquellos aspectos que, desde su percepción de la realidad, aún prevalecen en la sociedad actual y están basados en convencionalismos o estereotipos sexistas, y cómo pueden obstaculizar el camino hacia la igualdad en la sociedad actual.

4) Elaborarán entre todos unas conclusiones. Esta fase del trabajo requiere la implicación del grupo para llegar a través del diálogo y el consenso a acuerdos y resultados finales, que no siempre contentarán a todos/as por igual, de ahí las dificultades de la presente fase. Se trata de superar obstáculos a través de actitudes de cooperación, colaboración y coordinación.

5) Para presentar las conclusiones elaborarán un power point, donde podrán contemplar entre otros aspectos los siguientes: frases textuales que les hayan parecido especialmente significativas de las entrevistas realizadas, análisis evolutivo de los principales bloques temáticos abordados, Anecdotario (ideas, reflexiones, encuentros y desencuentros, emociones y sentimientos que les ha despertado escucharlas, relatos de situaciones que les parecen injustas, desigualitarias, excluyentes, degradantes...).

6) También pueden incorporar, lo cual sería muy enriquecedor e ilustrativo, fotografías de sus madres y sus abuelas. A través de las mismas podemos comentar, por ejemplo, la estética derivada del discurso ideológico y religioso que se transmitía o dialogar con ellos si es posible apreciar en estas imágenes algunas características definitorias del modelo de feminidad. Otros materiales complementarios podrían ser, por ejemplo, extractos de cartas, para analizar cómo se expresaban o cuáles eran sus anhelos.

7) Posteriormente, elegirán entre todos/as un portavoz que llevará la reflexión conjunta al debate del 
grupo-clase, un debate que no se afrontará el mismo día, sino en la próxima sesión, con el fin de dejar un espacio de reflexión al alumnado, refrescar el debate y afrontarlo con ganas renovadas, pues el rendimiento y la motivación del mismo disminuye considerablemente cuando dedican mucho tiempo a un mismo tema.

8) En la siguiente sesión, y actuando el profesorado de ambas asignaturas como moderador/a se iniciará el debate, partiendo en primer lugar de una exposición corta y concisa por parte de los distintos portavoces y a partir de ahí generar el debate. También puede enriquecerse el mismo, por ejemplo, con lecturas y reflexiones de la época por parte de los y las docentes que le parezcan especialmente relevantes para la consecución de los objetivos de la propuesta didáctica, trasposición de algunas de las reflexiones a su cotidianidad, etc.

Nuestra propuesta didáctica está planteada en futuro puesto que aún no ha sido implementada en el aula. El trabajo con las familias es la apuesta más importante de la misma, así como las conclusiones y consecuencias que puedan derivarse de la puesta en común del trabajo tanto en el hogar como en el aula.

\section{Conclusiones}

La propuesta didáctica que hemos presentado plantea como objetivo general analizar las pervivencias, pero también los cambios y rupturas, con la esperanzadora visión de la evolución experimentada tanto por las entrevistadas como por nuestro alumnado, porque estamos convencidos de la capacidad de nuestra sociedad, y en especial de las generaciones futuras, para hacer frente a unos argumentos ideológicos que en su día contribuyeron a mantener a las mujeres en la sumisión, y que no sólo no han desaparecido, sino que como expone Encarnación Barranquero (2012, p. 15) se están reactivando con fuerza significativa en los últimos años, instrumentalizando desde el más rancio conservadurismo discursos e imágenes profundamente antifeministas, con estereotipos renovados, pero fundamentados ideológicamente en el patriarcado.

Escuchar a sus madres y a sus abuelas es necesario para que entiendan que no se puede realizar un análisis crítico de los sucesos históricos sin atender a la contextualización espacio-temporal $\mathrm{y}$, consecuentemente ideológica y que siempre tendremos que considerar que nuestro análisis es artificial y subjetivo, porque lo realizamos desde nuestro presente. Por otra parte, entender el momento que vivieron y los fundamentos de su formación es determinante para empatizar, para ponerse en el lugar de ellas y comprenderlas, también para reconocerse a ellos/ellas mismos/ as en dichos fundamentos que pueden estar aún en muchos de sus principios y certezas, en su forma de entender el mundo y discernir, en un periodo clave de su maduración y formación integral, 
qué principios ideológicos heredados comparto y cuales, fruto de la formación, experiencia compartida y socialización, cuestiono. La implementación de la propuesta didáctica planteada permitirá realizar un acercamiento intergeneracional que facilite el encuentro, la comprensión y diálogo entre hombres y mujeres, generando en nuestro alumnado la capacidad para implicarse de una manera crítica en el presente que están viviendo, sentirse parte del proceso histórico que están investigando y, comprometerse con el presente, desde la consecución de la igualdad.

Como defendió uno de los referentes más significativos en Historia Oral, Paul Thompson (1988, p.12), a través de ella puede vehicularse un movimiento que ayude a vivir mejor y nos aproxime a las experiencias de los demás. El colectivo femenino ha participado durante mucho tiempo, en nuestro país, de su propia discriminación, con su abnegada subordinación, llegó el momento de repensar a las mujeres como sujetos de su propia historia.

\section{Bibliografía}

ARENAS FERNÁNDEZ, M.G. (1996).

Triunfantes perdedoras. Investigación sobre la vida de las niñas en la escuela. Málaga, Universidad de Málaga.

BALLARÍN DOMINGO, P. (2001). La educación de las mujeres en la España Contemporánea (siglos XIX-XX). Madrid: Síntesis Educación.
BENADIBA, L. (2013). Espacios y prácticas en la historia oral. Experiencias desde el compromiso. Argentina: Maipue.

CABRERA GARCÍA, O. (2008). Relaciones de género en investigaciones basadas en experiencias de Historia Oral. Palobra, $\mathrm{n}^{\circ}$ 9, 22-31.

CARREÑO, M. (2003-2004). Chicas de la posguerra. Un análisis sobre el aprendizaje de género más allá de la escuela. Historia de la Educación, $\mathrm{n}^{\circ}$ 22-23, 79-104.

CASANOVA NUEZ, E. (2009). La conformación política en los espacios públicos durante la inmediata postguerra. En Usos públicos de la Historia: comunicaciones al VI Congreso de la Asociación de Historia Contemporánea, Zaragoza.

CLIMENT FERRER, F. (1916). El ama de casa. Cultura femenina. Barcelona: Biblioteca de cultura y civismo.

FOLGUERA, P. (2005). La construcción de lo cotidiano durante los primeros años del franquismo. Ayer, $\mathrm{n}^{\circ} 19$, 165-188.

FELIU TORRUELLA, M. y HERNÁNDEZ CARDONA, F.J. (2013). Didáctica de la Guerra Civil española. Barcelona: Grao.

FERNÁNDEZ MIRANDA, T. (1961). El hombre y la sociedad. Madrid: Doncel. HALBMAYR, B. (2010). Las dificultades de interpretar con métodos de Historial Oral. Historia, Antropología y Fuentes Orales, nº 43, 157-169. 
HUGUET, M. (2013). Memoria del primer franquismo: mujeres, niños y cuentos de infancia. En Cagnolati, A, Sobre Donne e bambini. (En prensa).

LLONA, M. (2012) (coord.). Entreverse: teoría y metodología práctica de las fuentes orales. Bilbao: Universidad del País Vasco.

MORENO MARIMÓN, M. (2000). Cómo se enseña a ser niña: el sexismo en la escuela. Barcelona: Icaria.

MORENO SARDÁ, A. (1987). El arquetipo viril de la historia. Barcelona: Edicions de les Dones.

PEINADO RODRÍGUEZ, M. (2012). Enseñando a señoritas y sirvientas. Educación femenina y clasismo en el franquismo. Madrid: Catarata.

PEINADO RODRÍGUEZ, M. (2013). La estigmatización de la soltería en la España franquista. (En prensa).

PEINADO RODRÍGUEZ, Matilde y ANTA FÉLEZ, Jose Luis. (2013). Educar para el matrimonio en femenino: modelos y prácticas en la lite- ratura de posguerra. Athenea Digital, $\mathrm{n}^{\circ}$ 13(2), 35-46.

RODRÍGUEZ LÓPEZ, S. (2014). "Desinhibidas" las mujeres que rompieron los muros del franquismo. En Ledesma y Peinado (coords.). Homenaje a Carmen de Michelena. Jaén: Universidad de Jaén.

SUBIRATS, M. (1988). Rosa y azul: la transmisión de los géneros en la escuela mixta. Madrid: Instituto de la Mujer.

SUBIRATS, M. (1994). Conquistar la igualdad: la coeducación hoy. Revista Iberoamericana de Educación, $\mathrm{n}^{\circ}$ 6, 1-16.

THOMPSON, P. (1992). La voz del pasado. La historia oral. Río de Janeiro: Paz e Terra.

TRIADÓ, C, VILLAR, F (coord.) (2008). La relación entre abuelos/as y sus nietos/as adolescentes: comparación de perspectivas generacionales. Infancia y aprendizaje, $\mathrm{n}^{\circ} 31$ (3), 385398. 